\title{
A Prospective Longitudinal Study Evaluating The Influence of Immunosuppressives and Other Factors On COVID-19 in Autoimmune Rheumatic Diseases
}

\author{
Abhishek Patil \\ Manipal Hospital \\ Chanakya K \\ St. John's Medical College Hospital \\ Padmanabha Shenoy \\ CARE Hospitals
}

Chandrashekara S

ChanRe Rheumatology and Immunology Centre

Vikram Haridas

Arthritis Superspeciality centre

Sharath Kumar

OARC

\section{Manisha Daware}

Narayana Health

Ramya Janardana

St. John's Medical College Hospital

\section{Benzeeta Pinto}

St. John's Medical College Hospital

\section{Ramaswamy Subramaniam}

JSS Medical College and Hospital

Nagaraj $S$

Columbia Asia

Yogesh Preet Singh

Manipal Hospital

Shweta Singhai

Sakra Hospital

Ramesh Jois

Vikram Hospital

Vikramraj Jain

Bhagwan Mahaveer Jain Hospital 


\section{Srinivasa C}

Fortis Hospital

BG Dharmanand

Vikram Hospital

Chethana Dharmapalaiah

Aster CMI

\section{Sangeetha KN}

Anagha Hospital

\section{Vijay K Rao}

Manipal Hospital

Vineeta Shobha ( $\nabla$ vineeta.s@stjohns.in )

St. John's Medical College Hospital

\section{Research Article}

Keywords: Autoimmune rheumatic diseases, SARS-CoV-2 infection, risk factors, outcome, hydroxychloroquine, glucocorticoid, immunosuppressants.

Posted Date: August 24th, 2021

DOI: https://doi.org/10.21203/rs.3.rs-805748/v1

License: (c) (i) This work is licensed under a Creative Commons Attribution 4.0 International License. Read Full License 


\section{Abstract \\ Background}

We conducted this study to identify the influence of prolonged use of hydroxychloroquine(HCQ), glucocorticoids (GC) and other immunosuppressants (IS) on occurrence and outcome of COVID-19 in patients with autoimmune rheumatic diseases (AIRDs).

\section{Methods}

This was a prospective, multicenter, non-interventional longitudinal study across 15 specialist rheumatology centers. Consecutive AIRD patients on treatment with immunosuppressants were recruited and followed up longitudinally to assess parameters contributing to development of COVID-19 and its outcome.

\section{Results}

COVID-19 occurred in 314(3.45\%) of 9212 AIRD patients during a median follow up of 177 (IQR 129,219) days. Long term HCQ use had no major impact on the occurrence or the outcome of COVID-19. Glucocorticoids in moderate dose $(7.5-20 \mathrm{mg} /$ day) conferred higher risk $(R R=1.72)$ of infection. Among the IS, Mycophenolate mofetil (MMF), Cyclophosphamide (CYC) and Rituximab (RTX) use was higher in patients with COVID 19. However, the conventional risk factors such as male sex (RR = 1.51), coexistent diabetes mellitus $(R R=1.64)$, pre-existing lung disease $(R R=2.01)$ and smoking $(R R=3.32)$ were the major contributing risk factors for COVID-19. Thirteen patients $(4.14 \%)$ died, the strongest risk factor being pre-existing lung disease $(R R=6.36, p=0.01)$. Incidence ( $(17.5$ vs 5.3 per 1 lakh (Karnataka) and 25.3 vs 7.9 per 1 lakh(Kerala) ) and case fatality (4.1\% vs $1.3 \%$ (Karnataka) and $4.3 \%$ vs $0.4 \%$ (Kerala)) rate of COVID-19 was significantly higher $(p<0.001)$ compared to the general population of the corresponding geographic region.

\section{Conclusions}

Immunosuppressants have a differential impact on the risk of COVID-19 occurrence in AIRD patients. Older age, males, smokers, hypertensive, diabetic and underlying lung disease contributed to higher risk. The incidence rate and the case fatality rate in AIRD patients is much higher than that in the general population.

\section{Key Message}

1. Long term HCQ use had no major impact on the occurrence or the outcome of COVID-19 in AIRD. 
2. Glucocorticoids in moderate doses increased the risk of COVID-19 in AIRD patients.

3. The incidence rate of COVID-19 is at least 3 fold higher and the case fatality rate is 4.6 times higher than that of the general population in the same geographic area.

4. The risk of contracting COVID-19 is higher in AIRD patients, who are elderly, male, smokers, hypertensive, diabetic or with an underlying lung disease.

\section{Introduction}

The coronavirus disease (COVID-19) pandemic has affected more than 131 million persons and led to over 2.8 million deaths across the world as of 4th April 2021(1). In the early part of the COVID 19 pandemic in China, it became clear that comorbidities such as diabetes (DM), hypertension (HTN), and advanced age are associated with poor outcome. (2) Patients with Autoimmune Rheumatic Disease (AIRD) have underlying immune dysfunction in addition to frequent use of glucocorticoids (GC) and other immunosuppressant (IS) medications. Hence it becomes imperative to identify the risk factors associated with Severe Acute Respiratory Syndrome Coronavirus 2 (SARS- COV2) infection and outcome in AIRD.

In addition, with the better understanding of the molecular pathways and cytokine networks in SARSCoV2 infection, the repurposing of the existing immunomodulatory drugs to curtail the hyperinflammatory state came to the forefront $(3,4)$. Early on in the pandemic, hydroxychloroquine (HCQ) was acclaimed as both a preventive and therapeutic treatment for COVID-19, but subsequent clinical trials have not found any benefit. Several immunomodulatory medications including glucocorticoids and biologicals, which may potentially inhibit one or more steps of the coronavirus life cycle or can counteract the amplified immune response were focused on amongst many others.(5)

Autolmmune Rheumatic Disease(AIRD) such as Rheumatoid arthritis (RA), Systemic lupus erythematosus (SLE), Systemic Vasculitis and several others are conventionally treated with HCQ in addition to other IS and GC. Dexamethasone has been evaluated in several clinical trials and was associated with a lower risk of mortality at 28 days in critically ill COVID-19 patients, compared to placebo or standard of care.(6) GCs form an important component of treatment for many of the AIRDs. Clinical trial protocols testing these molecules would normally exclude immunosuppressed patients.(7) Therefore, it is of significance to understand both the incidence and outcome of COVID-19 in AIRD who are already on treatment with these groups of medications.

The purpose of our study was three-fold. Firstly, through this prospective longitudinal study, we examined if the AIRD population already on long term HCQ treatment had any impact on occurrence or severity of COVID-19 than the general population. Secondly, we examined if the current use of GC and or IS would influence occurrence of COVID-19, or alter the intensity of associated hyperinflammation thereby reducing its severity in AIRD patients. Thirdly, to delineate the risk factors associated with occurrence and adverse outcome of COVID-19 in the AIRD cohort in our geographic region who were being followed up longitudinally during the 1 st wave in India. 
As we write this manuscript, India is experiencing a second wave of COVID-19 and in the foreseeable future it is likely to persist. Hence, it also becomes imperative that real-world data should define and help derive recommendations for COVID-19 in AIRD patients.

\section{Methods}

\section{Study Design}

This is a prospective, multicenter, non-interventional, longitudinal study involving 14 specialist rheumatology centers across Karnataka and one center in Kerala, India. Consecutive patients diagnosed with any of the AIRDs on treatment and follow-up with collaborating centers were recruited into this study from April-December 2020. The proposal was approved by respective ethics committees and written consent was obtained from all the participants.

\section{Data Collection}

Clinical information was recorded using a structured case record form (CRF) developed specifically for this study. Subsequently a virtual harmonization meeting was conducted across all the recruiting centers.

\section{Study population}

Inclusion criteria for this study participation was a diagnosis of AIRD across all age groups. Their baseline demographics, disease subsets, current and past immunosuppressants (IS) information was recorded, with specific focus on HCQ and GC. We recorded the current dose of glucocorticoid that the patients were using at the time of enrollment. Non-immune mediated rheumatologic disorders and those not on treatment with IS and or HCQ were excluded. All comorbidities, including pre-existing lung diseases were recorded through review of their medical records. Additional medication information including use of antihypertensives such as angiotensin converting enzyme inhibitor (ACEi) or angiotensin receptor blockers (ARBs) were recorded.

\section{Follow-up}

The patients were followed up at baseline and then at one, three and six months of initial recruitment. The data was recorded during visits to the hospital or by investigators initiated telephone calls by trained tele-callers (rheumatology nurses/ physician assistants). The information was sought regarding COVID19 like symptoms, exposure to known COVID-19 patients and results of any COVID-19 test [Reverse Transcription-Polymerase Chain Reaction(RT-PCR) or Rapid Antigen Test(RAT)] using a checklist. Further, those who tested positive on either or both of the tests were considered as suffering from COVID-19 and their outcome information was recorded. The data collection was halted at the time of decline of the first wave of COVID-19 in India. COVID-19 testing protocols for symptomatic infection or exposed contacts were as per Government of India recommendations.

\section{Statistical methods}


Descriptive statistics were reported as mean and SD for continuous variables, number and percentages for categorical variables. Association of COVID-19 and mortality with various characteristics of the study population was assessed using Chi square/Fisher's Exact test and Student $t$ test. Bivariate and multivariate log binomial regression analysis was performed to assess the predictors for COVID-19 positivity and mortality, considering the study design of prospective study (cohort study). Unadjusted and adjusted relative risk along with $95 \%$ C.I. were reported. Variables that showed probability value less than 0.10 in the bivariate analysis were considered for multivariate analysis. The unit for person-time for incidence computation (No. of COVID-19 cases/total person time at risk) in this study is reported as person-days which was computed as 177 days (median follow-up) for the study duration. P value less than 0.05 was considered statistically significant. Statistical analyses were carried out using SPSS version 25.0 .

\section{Results}

\section{Study Population}

A total of 9212 AIRD patients were recruited, the major disease subsets were RA(50.9\%), SLE(15.4\%), axial spondyloarthropathy (SpA) $(9.1 \%)$ and psoriatic arthritis(PsA)(8\%). The mean age of the cohort was 45.1 years (SD 14.3), $2 \%$ were in the pediatric age group ( $<18 \mathrm{yrs}$ ) and $77 \%$ were females. The median duration of underlying illness was $48(22,96)$ months. Their baseline characteristics, IS administered and comorbidities are detailed in Table 1. During the course of this study (median follow up 177 days; (IQR) 129,219), 314 patients (3.4\%) were diagnosed with COVID-19 based on lab confirmation (RT-PCR and/ or RAT). . 
Table 1

Comparison of clinical characteristics amongst COVID and non-COVID AIRD patients

\begin{tabular}{|c|c|c|c|c|}
\hline & $\begin{array}{l}\text { Overall } \\
9212(\%)\end{array}$ & $\begin{array}{l}\text { COVID positive } \\
314(\%)\end{array}$ & $\begin{array}{l}\text { COVID negative } \\
8898(\%)\end{array}$ & $P$ value \\
\hline Age in years & $45.1 \pm 14.3$ & $46.8 \pm 14.3$ & $45.1 \pm 14.2$ & 0.028 \\
\hline Gender & $2134(23.2)$ & $99(31.5)$ & 2035 (22.9) & $<0.001$ \\
\hline Male & 7075 (76.8) & $215(68.5)$ & $6860(77.1)$ & \\
\hline \multicolumn{5}{|l|}{ Female } \\
\hline Duration of AIRD in months & $2916(32.5)$ & $94(30.4)$ & $2822(32.5)$ & 0.658 \\
\hline $1-24$ & $1720(19.2)$ & $64(20.7)$ & $1656(19.1)$ & \\
\hline $25-48$ & $4343(48.4)$ & $151(48.9)$ & $4192(48.4)$ & \\
\hline \multicolumn{5}{|l|}{$>48$} \\
\hline Diagnosis & $4558(50.9)$ & $120(40.0)$ & $4438(51.3)$ & $<0.001$ \\
\hline RA & $1379(15.4)$ & $36(12.0)$ & $1343(15.5)$ & 0.07 \\
\hline SLE & $99(1.1)$ & $3(1.0)$ & $96(1.1)$ & 0.25 \\
\hline Inflammatory Myositis & $173(1.9)$ & $7(2.3)$ & $166(1.9)$ & 0.36 \\
\hline Systemic Sclerosis & $193(2.2)$ & $18(6.1)$ & $175(2.0)$ & $<0.001$ \\
\hline Systemic vasculitis & $716(8.0)$ & $21(7.1)$ & $695(8.1)$ & 0.52 \\
\hline PsA & $148(1.7)$ & $8(2.7)$ & $140(1.6)$ & 0.15 \\
\hline Sjogren's & $819(9.1)$ & $33(11.1)$ & $786(9.1)$ & 0.31 \\
\hline AxSpA & $58(0.6)$ & $4(1.3)$ & $54(0.6)$ & 0.84 \\
\hline Sarcoidosis & $11(0.1)$ & $2(0.7)$ & $9(0.1)$ & 0.15 \\
\hline Bechets & $720(8.0)$ & $45(15.0)$ & $675(7.8)$ & \\
\hline \multicolumn{5}{|l|}{ Others } \\
\hline HCQ use N(\%) & $5266(57.4)$ & 167 (53.2) & 5099 (57.5) & 0.125 \\
\hline Mean dose(mg) & $212(200,300)$ & $200(200,300)$ & $200(200,300)$ & 0.136 \\
\hline Duration(months) & $12(3,39)$ & $10(0,38)$ & $12(3,39)$ & 0.218 \\
\hline
\end{tabular}

Abbreviations: AIRD-Autoimmune rheumatic diseases, RA- rheumatoid arthritis, SLE- systemic lupus erythematosus, PsA- psoriatic arthritis, AxSpA- Axial spondyloarthritis, HCQ-hydroxychloroquine, TNFitumor necrosis factor alpha inhibitor, JAKinibs- janus kinase inhibitors, DM- diabetes mellitus, HTNhypertension, ACEi- angiotensin converting enzyme inhibitor, ARB- angiotensin receptor blocker 


\begin{tabular}{|c|c|c|c|c|}
\hline & $\begin{array}{l}\text { Overall } \\
9212(\%)\end{array}$ & $\begin{array}{l}\text { COVID positive } \\
314(\%)\end{array}$ & $\begin{array}{l}\text { COVID negative } \\
8898(\%)\end{array}$ & $P$ value \\
\hline Glucocorticoids N(\%) & $3459(37.7)$ & $122(39.0)$ & 3337 (37.7) & 0.647 \\
\hline Mean dose mg/day (\%) & $2652(79.5)$ & $91(73.4)$ & $2561(79.7)$ & 0.111 \\
\hline$<7.5$ & $395(11.8)$ & $22(17.7)$ & $373(11.6)$ & \\
\hline $7.5-20$ & $289(8.7)$ & $11(8.9)$ & $278(8.7)$ & \\
\hline \multicolumn{5}{|l|}{$>20$} \\
\hline Immunosuppression & $5494(60.0)$ & $152(49.0)$ & $5336(60.3)$ & 0.001 \\
\hline Methotrexate & $389(4.3)$ & $12(4.0)$ & $377(4.3)$ & 0.800 \\
\hline Azathioprine & $720(7.9)$ & $34(11.3)$ & $686(7.8)$ & 0.029 \\
\hline Mycophenolate & $58(0.6)$ & $8(2.7)$ & $50(0.6)$ & $<0.001$ \\
\hline Cyclophosphamide & $1811(19.7)$ & $46(15.1)$ & $1765(20.1)$ & 0.034 \\
\hline Leflunomide & $496(5.5)$ & $15(5.0)$ & $481(5.5)$ & 0.655 \\
\hline Tacrolimus & $149(1.6)$ & $11(3.5)$ & $138(1.6)$ & 0.007 \\
\hline Rituximab & $193(2.1)$ & $10(3.2)$ & $183(2.1)$ & 0.170 \\
\hline TNFi & $35(0.4)$ & $1(0.3)$ & $34(0.4)$ & 0.857 \\
\hline Secukinumab & $21(0.2)$ & 0 & $21(0.2)$ & 1.000 \\
\hline JAKinibs & $42(0.5)$ & $1(0.3)$ & $41(0.5)$ & 1.000 \\
\hline \multicolumn{5}{|l|}{ Iguratimod } \\
\hline Comorbidities & 993 (10.9) & $62(19.8)$ & $931(10.5)$ & $<0.0001$ \\
\hline DM & $1385(15.0)$ & $68(21.9)$ & $1317(14.9)$ & $<0.0001$ \\
\hline HTN & $366(4.0)$ & $28(8.9)$ & 338 (3.8) & $<0.0001$ \\
\hline \multicolumn{5}{|l|}{ Pre existing Lung disease } \\
\hline ACEi /ARBs & $898(9.9)$ & $39(12.6)$ & 859 (9.8) & 0.096 \\
\hline Yes & $8218(90.1)$ & $269(97.1)$ & 7841 (97.7) & \\
\hline \multicolumn{5}{|l|}{ No } \\
\hline Smoking & $85(0.9)$ & $9(2.9)$ & $76(0.9)$ & 0.002 \\
\hline $\begin{array}{l}\text { Abbreviations: AIRD-Aut } \\
\text { erythematosus, PsA- ps } \\
\text { tumor necrosis factor al } \\
\text { hypertension, ACEi- angi }\end{array}$ & $\begin{array}{l}\text { rheumatic } \\
\text { hritis, AxSpA } \\
\text { itor, JAKinib } \\
\text { onverting en }\end{array}$ & $\begin{array}{l}\text { es, RA- rheuma } \\
\text { I spondyloarthr } \\
\text { us kinase inhibi } \\
\text { inhibitor, ARB- }\end{array}$ & $\begin{array}{l}\text { arthritis, SLE- sys } \\
\text { HCQ-hydroxychlo } \\
\text { DM-diabetes me } \\
\text { otensin receptor }\end{array}$ & $\begin{array}{l}\text { ic lupus } \\
\text { dine, TNFi- } \\
\text { IS, HTN- } \\
\text { ker }\end{array}$ \\
\hline
\end{tabular}


HCQ and COVID-19 Overall, during the study period, $57.4 \%, 68 \%$ and $88 \%$ of the total cohort, RA and SLE, were being treated with HCQ respectively. The mean dose of HCQ was $212 \mathrm{mg} /$ day (SD 119). The median duration of HCQ use in the entire cohort was 12 months (IQR 3,39). In the overall cohort, HCQ use did not influence occurrence of COVID-19 (RR $=0.909, \mathrm{Cl}(0.715,1.154), p=0.432)$ or mortality $(p=0.097)$ (Table 2, Fig. 1). In the subgroup analysis of RA and SLE, there was no independent impact of HCQ on occurrence and outcome of COVID-19. 
Table 2

Factors associated with Mortality $(\mathrm{N}=13)$ in COVID-19 population:

\begin{tabular}{|c|c|c|c|c|c|c|}
\hline & \multicolumn{3}{|c|}{ Unadjusted } & \multicolumn{3}{|c|}{ Adjusted } \\
\hline & $\mathrm{RR}$ & 95\% C.I. & $\begin{array}{l}P \\
\text { value }\end{array}$ & RR & 95\% C.I. & $\begin{array}{l}P \\
\text { value }\end{array}$ \\
\hline Age & 1.053 & $1.012,1.096$ & 0.071 & 1.037 & $0.996,1.079$ & 0.079 \\
\hline Gender M:F & 1.357 & $0.456,4.044$ & 0.583 & & & \\
\hline RA & 1.475 & $0.487,4.465$ & 0.492 & & & \\
\hline SLE & 0.659 & $0.088,4.955$ & 0.685 & & & \\
\hline Duration of AIRD (months) & 1 & $0.534,4.835$ & 0.399 & & & \\
\hline $1-24$ & 1.606 & $0.048,3.201$ & 0.383 & & & \\
\hline $25-48$ & 0.393 & & & & & \\
\hline \multicolumn{7}{|l|}{$>48$} \\
\hline Diabetes Mellitus & 3.471 & $1.209,9.960$ & 0.021 & & & \\
\hline Hypertension & 2.233 & $0.755,6.607$ & 0.146 & & & \\
\hline $\begin{array}{l}\text { Pre-existing Lung } \\
\text { involvement }\end{array}$ & 6.362 & $\begin{array}{l}2.231 \\
18.130\end{array}$ & 0.001 & 4.315 & $\begin{array}{l}1.416 \\
13.150\end{array}$ & 0.010 \\
\hline Current Steroid use & 2.23 & $0.87-5.71$ & 0.09 & & & \\
\hline HCQ & 0.341 & $0.096,1.215$ & 0.097 & & & \\
\hline CYC & 2.41 & $0.36,16.1$ & 0.362 & & & \\
\hline MMF & 1.689 & $0.511,5.57$ & 0.390 & & & \\
\hline Rituximab & 1.72 & $0.25,11.8$ & 0.581 & & & \\
\hline ACEi/ARB & 1.259 & $0.290,5.468$ & 0.759 & & & \\
\hline Smokers & 6.162 & $1.593,23.83$ & 0.008 & & & \\
\hline \multicolumn{7}{|c|}{ Multivariate model adjusted for age, gender, diabetes, Lung involvement } \\
\hline $\begin{array}{l}\text { Abbreviations: AIRD-Autoim } \\
\text { erythematosus, HCQ-hydrox } \\
\text { ACEi- angiotensin convertin }\end{array}$ & $\begin{array}{l}\text { rheum } \\
\text { roquin } \\
\text { yme in }\end{array}$ & $\begin{array}{l}\text { atic diseases, } \\
\text { CYC- cycloph } \\
\text { ibitor, ARB- an }\end{array}$ & $\begin{array}{l}\text {-rheum } \\
\text { phamid } \\
\text { tensin }\end{array}$ & $\begin{array}{l}\text { id arthri } \\
\text { MMF- m } \\
\text { eptor blc }\end{array}$ & $\begin{array}{l}\text { S, SLE- syster } \\
\text { cophenolate I } \\
\text { ker }\end{array}$ & $\begin{array}{l}\text { lupus } \\
\text { etil, }\end{array}$ \\
\hline
\end{tabular}

GC and COVID-19 (Table 1, Fig. 1): In the entire cohort, 3459 (37.7\%) AIRD patients were using GC at the time of participation in this study. The use of GC was analysed in 3 groups viz. $<7.5 \mathrm{mg}, 7.5-20 \mathrm{mg}$, and $>$ $20 \mathrm{mg}$, almost four fifths (79.1\%) of them were using a dose $<7.5 \mathrm{mg} /$ day. In the univariate analysis, 
those on GC moderate dose category (7.5-20 mg), had the highest risk ( $R R=1.72$, C.I.(1.12,2.64), $p=$ 0.01 ) of COVID-19, which was substantiated in multivariate analysis (RR 1.57, C.I.(1.003,2.47), $p=0.048$ ). Current use of steroids trended towards moderate influence on mortality as well (RR 2.23, $\mathrm{Cl}(0.87-5.71)$ $p=0.09)$ (Table 2).

\section{Associations with other IS, biologics}

A higher association of COVID-19 positivity was noted with the use of cyclophosphamide (CYC) ( $p<$ $0.001)$ and mycophenolate (MMF) $(p=0.029)$ (Table 1). Amongst those on treatment with biologics, risk was higher with rituximab (RTX) $(p=0.007)$. In the multivariate analysis, CYC $[R R-4.2, C l(2.23,7.91) p<$ 0.001] and RTX [RR 2.4, $\mathrm{Cl} 1.35-4.32 \mathrm{p}=0.003$ ] use were independent risk factors associated with increased risk of COVID-19. (Fig. 1, supp Table 1). However, MMF $(P=0.39), C Y C(P=0.36)$ and RTX $(p=$ 0.58 ) use did not affect mortality (Table 2 ).

\section{Disease subsets}

We found that a lesser proportion of RA patients developed COVID-19 compared to other AIRDs (RR$0.642, \mathrm{Cl} 0.51,0.81, \mathrm{p}=0.041)$. Patients with systemic vasculitis had the highest risk of contracting COVID-19 $(p<0.001)($ Table 1).

\section{Comorbidities and other parameters}

The parameters associated with COVID-19 positivity were older age $(p=0.025)$, male sex $(p=0.001)$, smoking $(p=0.002)$, comorbidities such as DM $(p<0.0001)$, HTN $(p<0.0001)$, presence of underlying lung disease such as interstitial lung diseases, asthma, chronic obstructive pulmonary disease $(p<$ $0.0001)$ and smoking $(\mathrm{p}=0.002)$. The relative risk of occurrence of COVID-19 with $95 \% \mathrm{Cl}$ is detailed in Fig. 1 (Supp Table 1). Multivariate analysis adjusted for age, gender, DM, HTN, lung involvement and immunosupression use, it was noted that male sex [RR-1.51, $p=0.001]$, the coexistent DM [RR-1.64, $p=$ $0.001]$, underlying lung disease [RR-2.01, $p<0.0001]$, and smoking [RR-3.32, $p<0.0001]$ were the independent risk factors associated with the increased risk of COVID-19. Use of ACEi/ARBs had no significant impact on occurrence or outcome.

\section{Outcome of COVID-19}

Among the 314 COVID-19 patients, $13(4.14 \%)$ died. The factors associated with death are presented in Table 2. The pre-existing lung disease was the strongest risk factor associated with increased risk for mortality $(\mathrm{RR} 4.315, \mathrm{Cl}(1.416,13.15) \mathrm{p}<0.01)$ apart from conventional risk factors such as smoking and coexisting DM.

\section{Comparison of Incidence and mortality of COVID-19 with general population}

The incidence of COVID-19 in our cohort was significantly higher compared to the incidence in the general population $(p<0.0001)$ both in Karnataka and Kerala as depicted in Table 3. Case fatality rate was 4.5 
times higher ( $4.1 \%$ in AIRD cohort vs $0.9 \%$ in the general population) amongst the AIRD population.

Table 3

Comparison of COVID-19 incidence and mortality in AIRD vs general population:

\begin{tabular}{|lllll|}
\hline & Karnataka & \multicolumn{3}{c|}{ Kerala } \\
\hline & AIRD cohort & $\begin{array}{l}\text { General } \\
\text { population }\end{array}$ & AIRD cohort & $\begin{array}{l}\text { General } \\
\text { population }\end{array}$ \\
\hline Incidence rate & $\begin{array}{l}17.5 / 100,000 \\
\text { population }\end{array}$ & $\begin{array}{l}5.3 / 100,000 \\
\text { population }\end{array}$ & $\begin{array}{l}25.3 / 100000 \\
\text { population }\end{array}$ & $\begin{array}{l}7.9 / 100000 \\
\text { population }\end{array}$ \\
\hline $\begin{array}{l}\text { Case Fatality } \\
\text { rate (\%) }\end{array}$ & $9 / 221$ & $12080 / 918473$ & $4 / 93$ & $3070 / 760692$ \\
\hline $\begin{array}{l}\text { Incidence rates and mortality }(p<0.001) \\
\text { (both AIRD and general population) }\end{array}$ & $4.1 \%$ & $4.3 \%$ & $0.4 \%$ \\
\hline
\end{tabular}

\section{Discussion}

This longitudinal prospective study in AIRD patients was envisaged and initiated before we knew about differential risk factors for SARS-CoV2 infection and the impact of immunomodulatory therapies on its occurrence and outcome. Our AIRD cohort consists of a population from Karnataka and Kerala, who were followed up for approximately 6 months paralleling the time period of 1st peak of COVID-19 in our country. The incidence rate of COVID-19 was 3 fold higher in our cohort; as compared to the general population in the same region.(Table 3) Wang et al in systematic meta-analysis which included data from 26 studies and about 2000 patients, reported 1.5 times higher risk for COVID-19 in rheumatic patients $(\mathrm{OR}=1.53,95 \% \mathrm{Cl} 1.24-1.88)(8)$. In our cohort involving more than 9000 patients, RR is more than 3 times that of the general population.

Many of AIRD such as RA and SLE are treated routinely with HCQ, whereas others such as SpA, PsA and primary vasculitis are not. This brings out a natural selection of a cohort with and without the HCQ in AIRD, and allows us to assess the differential effect of this drug on occurrence as well as outcome of COVID-19. After adjusting for confounding variables, in our AIRD cohort, long term HCQ use did not influence either occurrence or mortality of COVID-19. The role of HCQ in COVID-19 prevention and management has been greatly debated with several authors reporting conflicting outcomes.(9-11) The potential beneficial role of HCQ in terms of preventing viral entry and replication may be fractional and its immunomodulatory effect could possibly be offset by the interaction with antiviral drugs in the acutely sick patients.(12) Through our study, we could not substantiate its role as a prophylactic immunomodulator despite its use for many months or years. Hence, we emphasize the use of HCQ in AIRD based on its need for the underlying rheumatic disease and not with respect to COVID-19 pandemic. 
In our cohort, we found an increased rate of infections with GC in moderate doses of 7.5-20 mg of prednisolone equivalent per day(RR 1.57) and not in lower dose ( $<7.5 \mathrm{mg} /$ day). Glucocorticoids have been consistently reported to increase the risk of both opportunistic and serious infections in AIRD.(13) However, in COVID-19 related hyperinflammation they have therapeutic value. Favalli et al. demonstrated a higher risk of COVID-19 in patients with AIRD, even at doses less than $2.5 \mathrm{mg} /$ day of prednisolone (OR of 2.89).(14) In its initial report of over 600 cases of COVID-19 in AIRD, Global rheumatology analysis network found a two times of odds of hospitalization with the use of steroids of $>10 \mathrm{mg}$ prednisolone /day.(15) Marques et al. demonstrated GC use to be associated with unfavorable outcomes of COVID-19 in rheumatic diseases.(16) With the demonstration of significant mortality benefit by the use of Dexamethasone in RECOVERY trial there has been renewed interest in the use of steroids in COVID-19.(6) In our study, we could not determine decisively the impact of steroids on mortality though there was a trend towards it. In line with the American College of Rheumatology recommendations, we advocate minimization of steroid use in AIRD to the lowest possible dose and shortest duration wherever feasible till further conclusive date becomes available.(17)

Amongst other ISs, MMF and CYC confer substantially higher risk of COVID-19 occurrence and mortality in our cohort, while other IS/csDMARDS did not have any major impact. Scire and colleagues from Italy; also found no significant influence of csDMARDs on the risk of hospitalization or mortality $\{0 R 0.54[\mathrm{Cl}$ 0.22-1.37] $p=0.188\}$.(18) Overall, the effect of csDMARDs on COVID-19 risk appears to be minimal. At the very least, appropriate use of csDMARDs for the underlying AIRD must not be withheld in the wake of COVID-19 pandemic.

Among the biologicals and targeted synthetic DMARDs (tsDMARDS), RTX exposure was greater among the COVID-19 patients in our cohort (3.5\% vs $1.6 \%$ ) (Table1). In a French cohort, RTX use was associated with the higher risk of severe COVID-19 disease (RR 3.26).(19) Pablos et al. from Spain reported a higher incidence of COVID-19 in AIRD treated with bDMRADS/ tsDMARDS \{OR $1.6095 \% \mathrm{Cl}(1.23-2.10)\}$ but not in those with cDMARDS.(20) Interestingly, at least 3 reports from different parts of the world describe a reduction in risk of severe COVID-19 with the use of bDMARDs particularly TNFi. $(18,21,22)$ There was no significant influence of TNFi or secukinumab use in our cohort. Because of small numbers and the differential dosing regimens of bDAMRDs, we can not derive any conclusion on their exact role in the outcome or occurrence of COVID-19. Similarly, the tsDMARDs did not influence the occurrence or outcome of COVID-19 in our cohort.

RA was the most common disease subset in our cohort, being the most common AIRD in the community. Patients with systemic vasculitis had the highest risk of contracting COVID-19 (18/189; 9.5\%), while RA had a lower risk (2.6\%). This could be related to the use of higher doses of steroids and more intense IS in systemic vasculitis compared to other disease subsets.

Most important risk factors for developing COVID-19 in our cohort were older age, male sex smoking, underlying comorbidities such as DM, HTN and pre-existent lung disease. Early on in this pandemic, it was understood that DM and HTN form the major risk for COVID-19. $(23,24)$ Bhandari et al. reported HTN 
and DM to be the major underlying conditions from Jaipur, India in 522 COVID-19 patients.(25) Preexisting lung disease and smoking carried the highest risk of COVID-19 related mortality in our cohort. This is similar to other cohorts of COVID-19 in rheumatic diseases where DM, HTN, age > 65 years and pre-existent lung disease were responsible for poor outcome.(26) A recent Brazilian study of a cohort of AIRD also found a higher requirement for emergency care in diabetic patients compared to non-diabetics (OR 1.38; $p=0.004) .(16)$ A recent meta-analysis also confirmed HTN $(O R=3.69,95 \% \mathrm{Cl} 1.41-9.69, \mathrm{P}=$ $0.008)$ and lung disease $(\mathrm{OR}=2.93,95 \% \mathrm{Cl} 1.64-5.23, \mathrm{P}=0.000)$ to predict hospitalization risk.(8) Therefore, the risk factors which increase the susceptibility to COVID-19 and adverse outcome in the general population hold true even in patients with AIRD.

Gender bias among patients with COVID-19 is a globally documented phenomenon. It is postulated to be the effect of sex hormones, stronger interferon response, higher helper \& cytotoxic activity of T cells, differential ACE2 expression and several others. $(27,28)$ In our COVID-19 infected cohort too, there was a preponderance of males in the multivariate analysis $(R R=1.51)$, however it did not influence mortality. Even though the number of smokers was relatively small in our cohort $(<1 \%)$, association with the COVID19 disease was quite noteworthy $(p=0.002)$. Leung et al demonstrated increased ACE2 gene expression in the bronchoalveolar lavage samples of smokers versus never-smokers to be the reason for increased susceptibility.(29) However, the data from China and Italy indicated a lower risk of COVID-19 and severity in current smokers. $(30,31)$ On the contrary, a large UK study involving more than $2.4 \mathrm{M}$ participants has demonstrated a higher risk of COVID-19 in current smokers (OR 1.14).(32)

Initial concerns regarding the use of ACEi/ ARBs surfaced due to the upregulation of ACE 2 receptors on epithelial cells which are a portal of entry for SARS-COV-2. $(33,34)$ However, a meta-analysis of 10 studies, found neither the risk of COVID-19 nor severity of infection to be increased with the use of ACEi/ ARBs.(35) In our cohort of patients with AIRD, we found no significant impact of ACEi/ ARB use on the risk of COVID-19 occurrence or mortality.

Case fatality rate in our cohort was $4.14 \%$ which is 4.6 times higher than that in the general population from the same geographic area (0.9\%). OpenSAFELY- an initiative by the NHS, analysed the risk factors associated with the occurrence of COVID-19 in more than 1.7 Million people in England.(36) They found a higher risk of COVID-19 related death (OR of 1.3) in patients with RA, SLE and Psoriasis.(36) In another systematic review and meta-analysis, the fatality rate was $7 \%$ in the entire analysis and $6.7 \%$ in the GRA cohort. (15)(37) In our cohort, the strongest risk factor associated with mortality was underlying lung disease. Furthermore, the disease subsets, immunosuppressants and other comorbidities did not have much influence on mortality in our cohort.

To the best of our knowledge this is the first longitudinal cohort of impact of COVID-19 on any immunocompromised or immunodeficient cohorts from India. Initial results of this cohort were published during the early part of the pandemic.(38) Strengths of our study are its prospective longitudinal noninterventional design, large sample size from specialist rheumatology centres, inclusion of RT-PCR or RAT confirmed COVID-19 patients and investigator initiated follow-up telecalls. Limitations of our study 
include inability to accurately assess the impact of disease activity on occurrence and outcome of COVID-19. As rheumatologists are not the primary physicians for COVID-19 care, we were not able to access precise information with regards to 02 therapy, hospitalization and ICU care. Also, the testing for COVID-19 in individual patients was as per Govt. of India, Govt. of Karnataka and Govt. of Kerala protocols which have undergone modifications as the pandemic progressed. Our data may not have captured all asymptomatically infected patients in this analysis. This could have biased the result and might have altered the reported incidence as well as mortality. Also the comparison of incidence and mortality of COVID-19 in AIRD with the general population might have been influenced by the differential age and sex composition in both the populations.

\section{Conclusions}

Long term HCQ use had no significant impact on COVID-19 occurrence and mortality in AIRD patients while moderate doses of GC increased the risk of infection. AIRD patients who are elderly, male, smokers, hypertensive, diabetic and those with underlying lung disease have a higher risk of contracting COVID-19. The incidence rate is at least 3 fold higher and the case fatality rate is 4.6 times higher than that of the general population in the same geographic region during the same time period. Hence, this group of AIRD regardless of age and other comorbidities, merits first access to the various protective measures implemented against COVID-19 .

\section{Declarations}

Ethics approval and consent to participate: Ethics approval was obtained from respective ethics committee (St. John's Medical College-IERB No-127/2020, Chanre Rheumatology and Immunology Center \& Research - CRICR/SN-130/099/2020, JSS Medical College-JSSMC/IEC/180820/12NCT/2020-21). Written consent was obtained from all the participants.

We hereby confirm that approval was provided for the study titled 'Role of HCQ in COVID-19 pandemic in Rheumatological disorder"

Consent for publication: consent to publish from the patient- Not Applicable

Availability of data and materials: The data and materials are available to all authors

Competing interest-None of the authors has any conflict of interest to disclose.

Funding: Karnataka Rheumatology Association

\section{Authors Contribution:}

1) Conception and design of the study- V, CS

2) Analysis and interpretation of data- VS, AP, CK, CS 
3) Data acquisition - All authors

4) Drafted the work and revised it critically for important intellectual content - AP, CK, VS, CS, VKR, BP

5) Approved the version to be published- All authors

6) Agree to be accountable for all aspects of the work in ensuring that questions related to the accuracy or integrity of any part of the work are appropriately investigated and resolved- All authors

Ethical Publication: We confirm that we have read the Journal's position on issues involved in ethical publication and affirm that this report is consistent with those guidelines.

Acknowledgement: We thank Ms Sumithra Selvam, Department of Biostatistics, St John's Research Institute, SJNAHS, Bengaluru, for her support.

\section{References}

1. Coronavirus Update (Live): $131,576,586$ Cases and 2,862,454 Deaths from COVID-19 Virus Pandemic - Worldometer [Internet]. [cited 2021 Apr 4]. Available from:

https://www.worldometers.info/coronavirus/

2. Guan WJ, Liang WH, Zhao Y, Liang HR, Chen ZS, Li YM et. al. Comorbidity and its impact on 1590 patients with COVID-19 in China: a nationwide analysis. Eur Respir J. 2020 May 14;55(5):2000547.

3. Sultana J, Crisafulli S, Gabbay F, Lynn E, Shakir S, Trifirò G. Challenges for Drug Repurposing in the COVID-19 Pandemic Era. Front Pharmacol [Internet]. 2020 [cited 2021 Apr4];11.Available from: https://www.frontiersin.org/articles/ 10.3389/fphar.2020.588654/ full

4. Fehr AR, Perlman S. Coronaviruses: an overview of their replication and pathogenesis. Methods Mol Biol Clifton NJ. 2015;1282:1-23.

5. Meyerowitz EA, Sen P, Schoenfeld SR, Neilan TG, Frigault MJ, Stone JH, et al. Immunomodulation as Treatment for Severe Coronavirus Disease 2019: A Systematic Review of Current Modalities and Future Directions, Clinical Infectious Diseases, 2021 Jun 15;72(12);e1130-e1143.

6. The RECOVERY Collaborative Group. Dexamethasone in Hospitalized Patients with Covid-19. N Engl J Med. 2021 Feb 25;384(8):693-704.

7. McEniery CM, Fisk M, Miles K, Kaloyirou F, Hubsch A, Smith J, et al. ChemoPROphyLaxls with hydroxychloroquine For covld-19 infeCtious disease (PROLIFIC) to prevent covid-19 infection in frontline healthcare workers: A structured summary of a study protocol for a randomised controlled trial. Trials. 2020 Jul 2;21(1):604.

8. Wang Q, Liu J, Shao R, Han X, Su C, Lu W. Risk and clinical outcomes of COVID-19 in patients with rheumatic diseases compared with the general population: a systematic review and meta-analysis. Rheumatol Int. 2021 May;41(5):851-61. 
9. Skipper CP, Pastick KA, Engen NW, Bangdiwala AS, Abassi M, Lofgren SM, et al. Hydroxychloroquine in Nonhospitalized Adults With Early COVID-19. Ann Intern Med [Internet]. 2020 Jul 16 [cited 2021 Apr 5]; Available from: https://www.ncbi.nlm.nih.gov/pmc/articles/PMC7384270/

10. Ghazy RM, Almaghraby A, Shaaban R, Kamal A, Beshir H, Moursi A, et al. A systematic review and meta-analysis on chloroquine and hydroxychloroquine as monotherapy or combined with azithromycin in COVID-19 treatment. Sci Rep. 2020 Dec;10(1):22139.

11. Gautret P, Lagier J-C, Parola P, Hoang VT, Meddeb L, Mailhe M, et al. Hydroxychloroquine and azithromycin as a treatment of COVID-19: results of an open-label non-randomized clinical trial. Int $\mathrm{J}$ Antimicrob Agents. 2020 Jul;56(1):105949.

12. New potential interaction with emergency COVID-19 medicine remdesivir. React Wkly. 2020;1810(1):3.

13. Youssef J, Novosad S, Winthrop K. Infection Risk and Safety of Corticosteroid Use. Rheum Dis Clin North Am. 2016 Feb;42(1):157-76.

14. Favalli EG, Bugatti S, Klersy C, Biggioggero M, Rossi S, De Lucia O, et al. Impact of corticosteroids and immunosuppressive therapies on symptomatic SARS-CoV-2 infection in a large cohort of patients with chronic inflammatory arthritis. Arthritis Res Ther. 2020 Dec;22(1):290.

15. Gianfrancesco M, Hyrich KL, Al-Adely S, Carmona L, Danila MI, Gossec L, et al. Characteristics associated with hospitalisation for COVID-19 in people with rheumatic disease: data from the COVID19 Global Rheumatology Alliance physician-reported registry. Ann Rheum Dis. 2020 Jul;79(7):85966.

16. Marques CDL, Kakehasi AM, Pinheiro MM, Mota LMH, Albuquerque CP, Silva CR, et al. High levels of immunosuppression are related to unfavourable outcomes in hospitalised patients with rheumatic diseases and COVID-19: first results of ReumaCoV Brasil registry. RMD Open. 2021 Jan;7(1):e001461.

17. Mikuls TR, Johnson SR, Fraenkel L, Arasaratnam RJ, Baden LR, Bermas BL, et al. American College of Rheumatology Guidance for the Management of Rheumatic Disease in Adult Patients During the COVID-19 Pandemic: Version 2. Arthritis Rheumatol. 2020;72(9):e1-12.

18. COVID-19 in rheumatic diseases in Italy: first results from the Italian registry of the Italian Society for Rheumatology (CONTROL-19) [Internet]. Clin Exp Rheumatol. [cited 2021 Apr 5]. Available from: https://www.clinexprheumatol.org/abstract.asp?a=15906

19. Avouac J, Drumez E, Hachulla E, Seror R, Georgin-Lavialle S, El Mahou S, et al. COVID-19 outcomes in patients with inflammatory rheumatic and musculoskeletal diseases treated with rituximab: a cohort study. Lancet Rheumatol. 2021 Mar;S266599132100059X.

20. Pablos JL, Abasolo L, Alvaro-Gracia JM, Blanco FJ, Blanco R, Castrejón I, et al. Prevalence of hospital PCR-confirmed COVID-19 cases in patients with chronic inflammatory and autoimmune rheumatic diseases. Ann Rheum Dis. 2020 Sep;79(9):1170-3.

21. Haberman RH, Castillo R, Chen A, Yan D, Ramirez D, Sekar V, et al. COVID-19 in Patients With Inflammatory Arthritis: A Prospective Study on the Effects of Comorbidities and Disease-Modifying 
Antirheumatic Drugs on Clinical Outcomes. Arthritis Rheumatol. 2020;72(12):1981-9.

22. Freites Nuñez DD, Leon L, Mucientes A, Rodriguez-Rodriguez L, Font Urgelles J, Madrid García A, et al. Risk factors for hospital admissions related to COVID-19 in patients with autoimmune inflammatory rheumatic diseases. Ann Rheum Dis. 2020 Nov;79(11):1393-9.

23. Fang L, Karakiulakis G, Roth M. Are patients with hypertension and diabetes mellitus at increased risk for COVID-19 infection? Lancet Respir Med. 2020 Apr;8(4):e21.

24. Gao C, Cai Y, Zhang K, Zhou L, Zhang Y, Zhang X, et al. Association of hypertension and antihypertensive treatment with COVID-19 mortality: a retrospective observational study. Eur Heart J. 2020 Jun 7;41(22):2058-66.

25. Bhandari S, Singh A, Sharma R, Rankawat G, Banerjee S, Gupta V, et al. Characteristics, Treatment Outcomes and Role of Hydroxychloroquine among 522 COVID-19 hospitalized patients in Jaipur City: An Epidemio-Clinical Study. J Assoc Physicians India. 2020 Jun;68(6):13-9.

26. Hyrich KL, Machado PM. Rheumatic disease and COVID-19: epidemiology and outcomes. Nat Rev Rheumatol. 2020 Dec 18;1-2.

27. Bwire GM. Coronavirus: Why Men are More Vulnerable to Covid-19 Than Women? Sn Compr Clin Med. 2020 Jun 4;1-3.

28. Peckham H, de Gruijter NM, Raine C, Radziszewska A, Ciurtin C, Wedderburn LR, et al. Male sex identified by global COVID-19 meta-analysis as a risk factor for death and ITU admission. Nat Commun. 2020 Dec;11(1):6317.

29. Leung JM, Yang CX, Tam A, Shaipanich T, Hackett T-L, Singhera GK, et al. ACE-2 expression in the small airway epithelia of smokers and COPD patients: implications for COVID-19. Eur Respir J [Internet]. 2020 May 14 [cited 2021 Apr 8];55(5). Available from:

https://www.ncbi.nlm.nih.gov/pmc/articles/PMC7144263/

30. Lippi G, Henry BM. Active smoking is not associated with severity of coronavirus disease 2019 (COVID-19). Eur J Intern Med. 2020 May;75:107-8.

31. Rossato M, Russo L, Mazzocut S, Di Vincenzo A, Fioretto P, Vettor R. Current smoking is not associated with COVID-19. Eur Respir J. 2020 Jun;55(6):2001290.

32. Hopkinson NS, Rossi N, El-Sayed_Moustafa J, Laverty AA, Quint JK, Freidin M, et al. Current smoking and COVID-19 risk: results from a population symptom app in over 2.4 million people. Thorax. 2021 Jan 5;thoraxjnl-2020-216422.

33. Wan Y, Shang J, Graham R, Baric RS, Li F. Receptor Recognition by the Novel Coronavirus from Wuhan: an Analysis Based on Decade-Long Structural Studies of SARS Coronavirus. Gallagher T, editor. J Virol. 2020 Jan 29;94(7):e00127-20, /jvi/94/7/JVI.00127 - 20.atom.

34. Li XC, Zhang J, Zhuo JL. The vasoprotective axes of the renin-angiotensin system: physiological relevance and therapeutic implications in cardiovascular, hypertensive and kidney diseases. Pharmacol Res. 2017 Nov;125(Pt A):21-38.

35. Biswas M, Kali MostSK. Association of angiotensin-converting enzyme inhibitors and angiotensinreceptor blockers with risk of mortality, severity or SARS-CoV-2 test positivity in COVID-19 patients: 
meta-analysis. Sci Rep. 2021 Dec;11(1):5012.

36. Williamson EJ, Walker AJ, Bhaskaran K, Bacon S, Bates C, Morton CE, et al. Factors associated with COVID-19-related death using OpenSAFELY. Nature. 2020 Aug 20;584(7821):430-6.

37. Xu C, Yi Z, Cai R, Chen R, Thong BY-H, Mu R. Clinical outcomes of COVID-19 in patients with rheumatic diseases: A systematic review and meta-analysis of global data. Autoimmun Rev. 2021 Apr;20(4):102778.

38. Shobha V, Chanakya K, Haridas V, Kumar S, Chebbi P, Pinto B, et al. Do all patients with rheumatic Diseases have a higher risk of COVID 19? Initial results from the Karnataka Rheumatology Association COVID 19 Cohort Study (KRACC). Indian J Rheumatol. 2021;0(0):0.

\section{Figures}

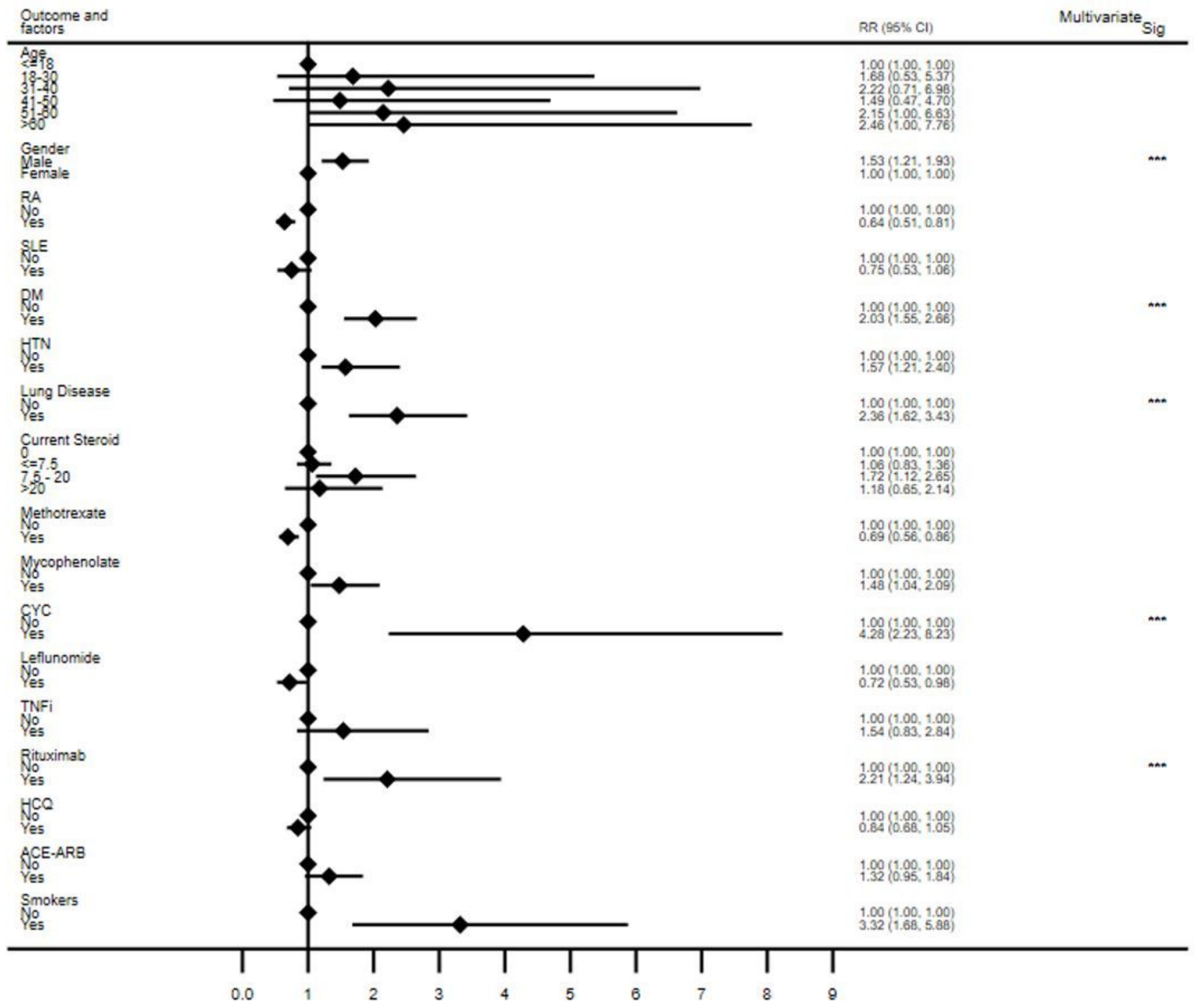

Figure 1 
Results of bivariate analysis to assess the factors associated with the risk of COVID-19 infection ... Significant values in Multivariate analysis; $\operatorname{Gender}(p=0.001), D M(p=0.001)$, Lund disease $(p<0.001)$, Steroid(7.5-20mg) $(p=0.04), C Y C(p<0.001)$, Rituximab $(p=0.003)$ Abbreviations: RA- rheumatoid arthritis, SLE- systemic lupus erythematosus, DM- diabetes mellitus, HTN- hypertension, CYC- cyclophosphamide, TNFi- tumor necrosis factor alpha inhibitor, HCQ-hydroxychloroquine, ACEi- angiotensin converting enzyme inhibitor, ARB- angiotensin receptor blocker.

\section{Supplementary Files}

This is a list of supplementary files associated with this preprint. Click to download.

- Supplimentarytable.docx 